\title{
Network analysis as a tool for humanitarian protection: research and practice
}

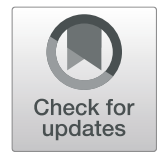

Romina Cachia ${ }^{1,2^{*}}$ and Daniel Holgado Ramos ${ }^{1}$

\begin{abstract}
In this article, we explore how network analysis could be used for humanitarian protection. Our objective is bringing together what is known about the role of networks for humanitarian aid intervention and examining how it could be used to respond to emergencies, through interventions which can aid and improve different aspects of the humanitarian protection. Based on this previous research, we develop a systematic framework aimed at informing researchers and practitioners on the different applications of network analysis and visualisations for humanitarian protection in two main areas: (1) to protect individuals and (2) to enable protection at the community level. We believe that the versatility of social network analysis is worth investigating in the context of humanitarian protection.
\end{abstract}

Keywords: Social networks, Social network analysis, Humanitarian protection, Personal network analysis

\section{Introduction}

In February 2000, Mozambique experienced devastating floods resulting in 699 deaths, hundreds of thousands of individuals displaced and over $27 \%$ of the population affected in one way or another. A significant number of non-government organisations (NGOs) were involved in the flood operations. In a study conducted following the disaster in which 65 NGOs were examined, it was found that the inter-organisational relations amongst NGOs has an influence on the success or failure of coordination of humanitarian aid operations (Moore, Eng, \& Daniel, 2003). In this study, international NGOs were found to be more central during the relief and recovery period and hence, were better positioned to monitor the flow of information and coordinate activities. While this has less importance for immediate intervention, as Moore et al. (2003) argue, this can have significant influence in local NGOs' capacity to deal, respond and recover from disaster in the long term.

Understanding the underlying network structure of inter-organisational relations illustrates another approach of addressing aid and protection. From a networks'

\footnotetext{
* Correspondence: romina.cachia@um.edu.mt

${ }^{1}$ University of Seville, Seville, Spain

${ }^{2}$ University of Malta, Msida, Malta
}

\section{Springer Open}

perspective, through the analysis of the average centrality of the NGOs inter-organisational relations, a pattern whereby international NGOs were more central and linked to each other and local NGOs on the periphery with less ties with international NGOs was identified. How does this structure influence humanitarian protection? As discussed by the researchers, once the emergency period ended and international NGOs reduced their aid, critical links within humanitarian aid network were lost leaving local NGOs with less capacity to aid and protect the population affected (Moore et al., 2003).

In this article, we will explore how networks can be used as a tool for humanitarian protection. Our objective is to pool together what is known about the role of networks for humanitarian aid intervention and examine how it could be used for protection. Based on previous research, we develop a systematic framework aimed at informing researching and practitioners on the different applications of network analysis and visualisations for humanitarian protection, in two main areas: (1) to protect individuals and (2) to enable protection at the community level.

\section{Networks matter}

Although social networks have existed since the beginning of societies (Barabasi, 2002), it was not until the 1930s when a systematic approach to the study of 
networks emerged (Freeman, 2004). The development of graph theory and computation advancement in the 70 s gave birth to network analysis as an interdisciplinary field. Researchers realised that social network analysis (SNA) provided a new tool for answering social and behavioural based patterns of relationships among interacting units (Wasserman \& Faust, 1994).

Broadly defined, SNA is the study of relations amongst a set of actors or units in a bounded group, focusing on the significance of patterns within a particular network. It relies heavily on graph theory and focuses on the relationships between entities rather than on the attributes of these entities. It is based on four major elements: (1) a structural intuition, (2) grounded by empirical data, (3) drawing on graphic imagery, and (4) the use of mathematical and/or computational models to perform the analysis (Freeman, 2004). Some examples may be communications between members of the group, economic exchanges between organisations and migratory flows between nations (Wasserman \& Faust, 1994).

Identifying which relations are interesting to study, and hence, delineating the boundary of the population is an important aspect of network analysis. The boundary may be already defined, as for instance, all volunteers in NGO X, or selected within a population because they meet some criteria, for instance, local survivors following a disaster who have lost their house. In the latter case, the network does not necessarily exist, but it is an aggregation defined by the researcher, as opposed to an institutionalised network or organisation already defined by its members.

Given its variability and the broad generality of its structural paradigm, the analysis of networks has been applied in a variety of contexts from international relations (Hafner-Burton, Kahler, \& Montgomery, 2009) to the health sector (Devillanova, 2008; Fernandez-Peña, Molina, \& Valero, 2018), mobility (Cachia \& Maya Jariego, 2018; Lubbers et al., 2010; Maya Jariego \& Holgado, 2015) and community intervention (Maya-Jariego \& Holgado, 2015; Maya Jariego, 2016; Valente, Palinkas, Czaja, Chu, \& Brown, 2015), to mention a few. All of these studies rely on the premise that networks matter and can constrain or facilitate social action (Hurlbert, Haines, \& Beggs, 2000).

As an analytical tool aimed at examining social relations, we would like to review and investigate how the study of these relations may be used to respond to emergencies, through interventions which can aid and improve different aspects of the humanitarian protection processes. We believe that the versatility of social network analysis is worth investigating in the context of humanitarian protection.

For the context of this paper, and given the lack of agreement on a common definition of humanitarian protection, our understanding of humanitarian protection is framed around activities and actions aimed at ensuring the right of individuals (Giossi Caversazio, 2001). Protection activities vary from microactions that seek to prevent abuse in a specific area to macroactions aimed at moving society as a whole to ensure human rights (Giossi Caversazio, 2001; O'Callaghan \& Pantuliano, 2007), from ensuring the provision of material assistance (food, water, shelter, etc.) to medical assistance, physical integrity, psychological wellbeing and dignity (European Commission, 2016). It is generally based on three types of inter-related activities: responsive action aimed at stopping or treating the immediate effect of abuse, remedial action which helps people live with long term effects of abuse and restitution or rehabilitation, aimed at creating an environment where the full rights of the individual are respected (Inter-Agency Standing Committee, 2002). While the responsibility of protection lies mainly with the state, in general, there is increasingly more acceptance towards the idea that protection is a core component of diverse aid agencies and not limited to those with a protection mandate (Jaspars \& O'Callaghan, 2010; O'Callaghan \& Pantuliano, 2007).

\section{Applications of network analysis}

Network theory is one of the few theoretical and methodological developments in social sciences that allows a multilevel analysis, from small groups to large systems, through organisations, movements or national and international systems (Kadushin, 2012). It is applicable to various types of networks, social, egocentric or organisational. In this respect, it allows an analysis of the structure of relations between different entities and actors involved in humanitarian protection, from the recipients of aid and their personal ties to the organisations involved in providing the protection or the nations in which these processes take place.

Its unique features also allow for specific disaster response analysis, for instance, through analysis of atypical structures, the need for new ties for collaboration and resource sharing and the identification of members and measuring their relations in the network in populations which are constantly changing (Varda, Forgette, Banks, \& Contractor, 2009). Different types of data can be extracted from diverse entities, resulting in a more amplified understanding of issues or problems in an area. For example, following an earthquake, a multilevel analysis can provide a more accurate interpretation of an issue. Let us say, we decide to intervene primarily with the victims using personal networks analysis, so as to understand their level of protection. Through this data, we learn that the victims are particularly anxious because their current shelters are only temporary and not everyone have social ties on whom they can rely for longer type of accommodation. In parallel, we also examine 
collaboration between aid agencies involved in the crisis. From this data, we identify a conflict in the structure of the network, which explains partially why longer-term shelter solutions have not to be resolved, even though, there is an NGO specifically dedicated to ensure longterm accommodation for victims.

Network analysis also provides tools to investigate the link between behavior and structure. Personal and social networks are created through the behavior of individuals and organisations that, in turn, generate consequences in these individuals and organisations. An intervention prior to a flood, whereby effort is concentrated in nurturing community ties might lead to stronger cohesive structures following a disaster.

As a flexible tool, it also allows the combination and feedback with other social research methods (Domínguez \& Hollstein, 2014), as well as the respondents involved in the study. The study on the Mozambique floods mentioned at the beginning of the article is a good example of this. Prior to applying network analysis, the researchers did field observations, field interviews and key-informant interviews to better understand and assess the degree to which communities were affected by the floods (Moore et al., 2003). Eventually, network analysis was conducted based on already existing data on collaboration and cooperation between NGOs.

In the context of humanitarian protection, this is important to underline because often network data is not easily attainable and might need to be complemented with other methods and instruments, such as in-depth interviews or surveys. Moreover, the fact that its modus operandi often allows the actors to discuss the network can also provide additional information which could be critical when it comes to design the intervention.

For instance, undocumented immigrants may not be willing to disclose their contacts in their networks when asked directly to list their ties, for fear of being located by the police. When one is in crisis, it might be hard to understand that this form of direct questioning typical of personal network analysis has nothing to do with state regulations. However, they might be willing to sit down for an in-depth interview and talk about their ties and draw their network, without disclosing their ties' identity. Moreover, the time with the participants might be limited and thus does not allow for long and timeconsuming instruments, often associated with network analysis. But a question on networks could well be inserted in other instruments, as has been successfully demonstrated in the General Social Survey in the USA (McPherson, Smith-Lovin, \& Brashears, 2006).

The versatility of network analysis as a tool for examining and identifying where humanitarian protection might be needed are listed in Table 1.

\section{Network analysis}

Network analysis offers a broader structural perspective of a set of relations. This is often derived from an intuitive notion that the structure of the relations forms a pattern that is significant, given it has consequences for the actors who are embedded in these relations (Freeman, 2004; Wasserman \& Faust, 1994). It differs from other methods of research in its focus on attributes of individuals, whereby these relations form structures which may either constrain or enable agents in their relations.

A crisis victim who is aware of the structure of his personal network is possibly more armed towards taking important decisions. Let us say, a refugee might prefer to stay in the camp where he is, where he has close ties and the structure of his personal network allows him to sell small products and earn a little bit of money, rather than move to a new camp where he might get closer to acquiring official papers, but at the expense of losing his current supportive network. Taking a broader view, the structure of the network can be highly informative, not just for the agents within the network, but also for outside intervention. A body managing foreign aid postemergency, might want to examine how local and foreign NGOs are already dealing with foreign aid. SNA provide a method for discovering patterns, measuring structures, and attempt to deduce which are the conditions producing such structures and its consequences (Fig. 1).

As a result of different historical traditions, two major approaches of network analysis emerged: (1) the sociocentric perspective which focuses on the pattern of ties within a group, what is normally referred to as social network analysis and (2) the direct relation of an actor with other actors from different social spaces, where the actor understudy is known as "ego" and the other actors directly connected to ego are called "alters". This approach is referred as personal network analysis (PNA). The major difference between the two approaches is that while the former aims at identifying a pattern of all the relations within a bounded system, for instance, all the relations within an NGO involved in an emergency following an earthquake, the latter gathers data on ego's network, with the aim to compare it with other egos' networks. An example would be comparing the personal networks of immigrants to examine how different typologies of mobility affect the provision of social support (Cachia \& Maya Jariego, 2018; Herz, 2015). PNA can also be used to estimate the size of personal networks, through the study of emotional support networks (McPherson et al., 2006) and/or through the identification of informal helper networks mobilised during a crisis (Chatters, Taylor, \& Neighbors, 1989). PNA is not an approach limited to 
Table 1 Network analysis applications

\begin{tabular}{|c|c|c|}
\hline Application & Description & Implications \\
\hline Focus on the relations & $\begin{array}{l}\text { The main unit of study is the relations between different } \\
\text { actors. Actors may vary between individuals to organisations, } \\
\text { NGOs and nations. }\end{array}$ & $\begin{array}{l}\text { - Allows us to identify problems or issues based on } \\
\text { the relations between actors. }\end{array}$ \\
\hline Multilevel analysis & $\begin{array}{l}\text { Different types of analysis can be conducted simultaneously, } \\
\text { from small groups to large systems, organisations, movements } \\
\text { or national and international systems. }\end{array}$ & $\begin{array}{l}\text { - Allows for data analysis from different types of } \\
\text { actors. } \\
\text { - Combining different sets of data can provide a } \\
\text { wider view of things and may provide a better } \\
\text { picture of where protection is needed. }\end{array}$ \\
\hline $\begin{array}{l}\text { Link between behaviour } \\
\text { and structure }\end{array}$ & $\begin{array}{l}\text { It can be used as a tool to investigate how the structure in } \\
\text { a network may be influencing behaviour and vice versa: a } \\
\text { tool to explain behaviour through the structure and } \\
\text { composition of the network. }\end{array}$ & $\begin{array}{l}\text { - Allows for a better understanding of where } \\
\text { intervention is needed. }\end{array}$ \\
\hline $\begin{array}{l}\text { Combination and feedback } \\
\text { with other social research } \\
\text { methods }\end{array}$ & $\begin{array}{l}\text { Network analysis can easily be combined with other } \\
\text { methods and instruments. }\end{array}$ & $\begin{array}{l}\text { - Ideal when network data is not easily attainable. } \\
\text { - Network data may be complemented with other } \\
\text { data sets. } \\
\text { - Allows space for respondents to discuss their } \\
\text { network. }\end{array}$ \\
\hline
\end{tabular}

the study of human beings. The ego may well be an organisation or an NGO.

\section{Networks as a tool for humanitarian protection}

How does this relate to humanitarian protection? When trying to dissect human protection from the SNA perspective, understanding the distinction and the role social relations play in the networks could be valuable, both in terms of intervention and in policy support. How do networks of individuals, communities and organisations affect preparation for a disaster, recovery and rebuilding? SNA could enable us to delve deeper into questions which would allow better intervention to take place: how does foreign aid overlap during emergency? How can foreign and local NGOs empower each other, especially after the emergency period is over? Can a personal network enable people in need of help to self-protect themselves?
How do the diverse typologies of the network structures influence protection? Which groups are most central to coordinate aid and relief in post-disaster networks (Varda et al., 2009)? In the next sections, we will aim to answer these questions and provide insights on how SNS could be utilized in the future for enabling humanitarian protection at the individual and community level.

\section{Individual}

In this section, we will explore different studies and network metrics which could be used to provide protection at the individual level. This is based on the idea that part of the work related to humanitarian protection may be addressed at actively supporting and reinforcing selfprotection. The section is divided in four parts, namely tracing the network, core components, weak ties and dynamic networks.

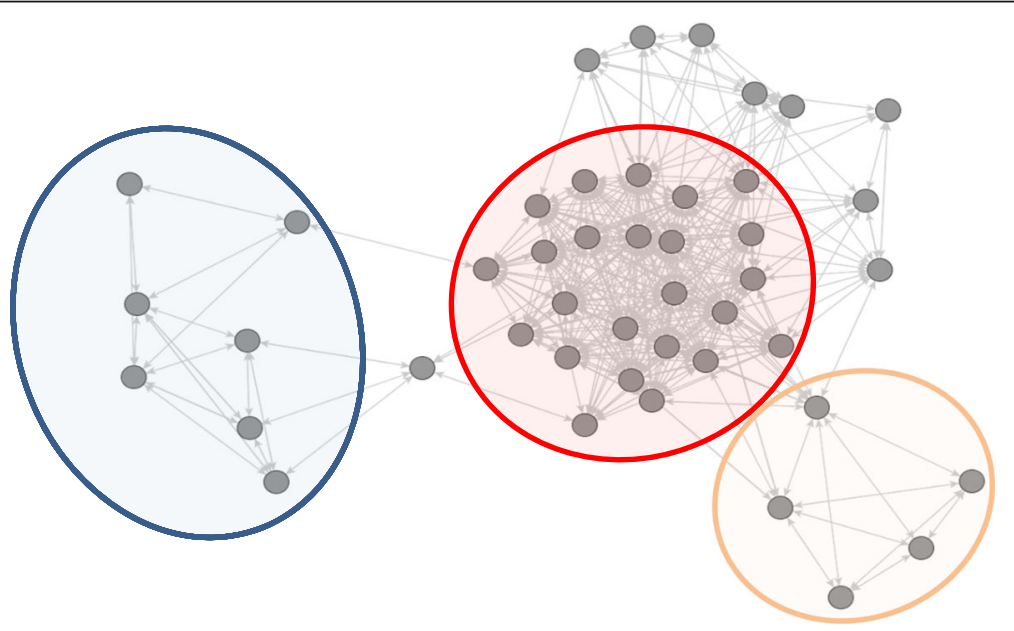

Fig. 1 Personal network with representation of different social spaces 


\section{Tracing the network}

In their study on urban refugees in Nepal, Thomas et al. (2011) found that in the absence of official documents and formal recognition, refugees turned to their network for recognition. Primary relations enabled refugees develop better coping mechanisms. Similarly in precarious contexts, where support from civil society and the state were lacking or weak, the personal network was found to be indispensable for daily survival (Suter, 2012; Van Wijk, 2010). It is well known by now that the disposition of a social networks is positively correlated with better health, both physically and psychologically (Cohen \& Syme, 1985; Umberson \& Montez, 2010). When people face emotional problems and in moments of crisis, they resort primarily to their intimate ties rather than to professional mental health services (Cassel, 1974; Cobb, 1976).

In contexts where displaced individuals are not formally recognised by the state, recognition by the people in their personal network can act as a stress reliever and provide a tool for coping with the stressful situation. Consequentially, personal networks could be used as a tool for mitigating the stress of resettlement, by bolstering the existing networks that exist, as well as by enabling them to rebuild pre-existing networks through reunification (Kingsbury et al., 2018). They may also be used as tools for self-protection, actively supporting and reinforcing coping strategies (Addison, 2009). Displaced individuals tend to develop transnational networks, whereby ties are created and maintained in another location, often the place of origin of the migrant (Cachia \& Maya Jariego, 2018; Lubbers et al., 2010; Wissink \& Mazzucato, 2018). Affected individuals might not be consciously aware of their transnational network. Hence, an approach to protection at the individual level may be utilizing the personal network to ensure that victims know their network, feel recognised within their network, have a network of social support at their disposal, and are able to build a new network.

In order to enable individuals to trace their network and know who is in their personal network, a personal network instrument known as the name generator could be used. It is an instrument which assists people to enumerate people who are in their personal network, based on a relation defined prior to the data collection, for instance, people who they rely on for social support or people with whom they can reside for some time following a crisis. Questions might be used as prompters to enable people enumerate a list of names. For instance, who are the people you talk to when you are sad? Or, who are the people you would contact if you need to borrow some money? Social and psychological support may be identified through different questions specifically designed for this purpose (Marin \& Hampton, 2007). This tool also allows for the estimation of the size of the network size and can especially be effective in hard-tocount populations, such as women who have been raped or civilians killed in wars (Bernard \& Ryan, 2010). Once the people have been listed, a matrix is created reporting the relations between the people listed. The matrix can be created during the intervention or afterwards.

Visualisations are also effective tools which can be used to enable people to trace their networks. The personal network can be depicted through hand-drawn maps or through programmes such as Vennmaker, which allow the participants to create an automated version of their network in real-time. As an interactive instrument, visualisations tend to be less intrusive and are effective in summarising information of complex structures (Gamper, Schönhuth, \& Kronenwett, 2012), while also providing an integrated view of relations which is often hard to acquire through narratives (qualitative analysis) or tables (quantitative analysis) (Ryan \& D'Angelo, 2018). This tool is also useful in helping people becoming aware of potential supportive ties in their networks enabling victims to rebuild their network, activate latent ties which could be instrumental in this moment in their lives or remember ties which they might have forgotten, as for instance, transnational ties in the context of displaced individuals.

Using specific name generators can also enable victims or those providing the aid to identify ties related to abuse or violence. Questions prompts such as: who are the people you would rather avoid because you are afraid, they may harm you or your family? Or who in the past few months have caused you harm, could reveal important information in a network. Once abuse or violence is identified in a network, actions can be taken to provide support for people living with abuse, to ensure medical and psychosocial care is provided and where possible and to try and stop the abuse or violence.

Various network metrics may also be used to enable people feel recognised within their network. Identification of groups and cliques could be used as a tool to explore the level of recognition one experiences in each of these groups and how such recognition can be improved. Structural holes in the structure of the network can also be used to identify gaps in the network, so as to work out effective strategies on how to fill such gaps.

\section{Core components}

The structure of individual's personal network prior to a crisis can affect the degree to which these networks ties are activated when looking for help in both the preparation and recovery phase of a crisis (Hurlbert et al., 2000). Individuals embedded in densely knit networks, often consisting of kin, close friends and ties with homogenous qualities to ego, are more likely to rely on this part of the network (Hurlbert et al., 2000) and are more likely to receive support in routine and emergency 
situations than people with diffused networks (Granovetter, 1983; Haines, Hurlbert, \& Beggs, 1996; Wellman \& Wortley, 1990). It has been demonstrated that disaster victims are more likely to activate their kinship ties when they are in need or in crisis (Quarantelli and Dynes 1977; Marsden 1987; Chatters et al. 1989; Shavit et al. 1994; Haines et al. 1996; Hurlbert et al. 2000; McPherson et al. 2006).

These ties, often referred to as strong ties, refer to contacts in one's network with whom the person has great intimacy, spend a lot of time, show reciprocity and have emotional intensity (Granovetter, 1973) and have been positively correlated with higher provision of social support (Wellman \& Wortley, 1990) and social influence. Densely knit network component is also a good basis for cooperative activities (Wellman, 1979) and has been positively linked to better health, lower level of depression, especially in the short-term recovery phase of a crisis (Haines et al., 1996) and access to medical treatment (Menjívar, 2002).

People with greater social capital tend to be more committed towards their communities and are more likely to mobilize collective action (Ellison, Steinfield, \& Lampe, 2007). Such bonding social capital, generally found within densely knit cliques, is important for enhancing resilience given they facilitate the internal transmission of information and knowledge (Putnam, 2000).

Moreover, core networks are also crucial conduits to key informal support networks often emerging from bottom-up, self-organised initiatives and which can be indispensable during the preparation and recovery phase of a crisis (Hurlbert, Beggs, \& Haines, 2006; Li, Chen, \& Suo, 2015). Individuals whose core network is sparser and heterophilic, and who in the past relied less on this core network, are less likely to connect with the core network for support in a crisis and hence might also lack this link to informal support.

A follow-up study on the earthquake in Ya'an City in China found that while the Chinese government had developed a rapid system in supplying relief supplies and social sources after a disaster, victims were more likely to seek assistance from their core network and would rather participate in self-organised activities, as opposed to government-organised ones. These informal networks based on social capital were more effective because they tend to be less affected by failures in formal systems which could have been greatly affected by the disaster. Indeed, communities with good social capital have been found to perform well during the rehabilitation period of an earthquake (Nakagawa \& Shaw, 2004), mainly as a result of collective action prompted from spontaneous cooperation (Adger, 2003).

In this section, we have seen how a densely knit core component of a network is instrumental when it comes to facing or recovery from a crisis. Not only it ensures support from close ties leading to better resilience, but it is also a path to a variety of informal support networks which tend to be related to cooperation and selforganisation during a crisis. Hence, structural metrics of SNA could be useful in identifying the different components and cliques in a network and examine how such groups can be activated during a crisis or following a crisis.

Using centrality measures, in particular degree central$i t y$, we can explore the degree of connectivity in the network, that is, how victims are directly connected to other people a high degree centrality

People whose networks are sparse and heterogenous might need help in establishing or identifying the core part in their network, and given in moments of crisis, this part of the network is the most reliable. A high degree centrality can enhance resilience by facilitating social support, local knowledge and trust. Moreover, as we have seen, the composition of the network, that is, the attributes of the respondents (McCarty, Molina, Aguilera, \& Rota, 2007), is also an important feature of the core network. This could be measured through examining the attributes of the alters mentioned in a network. In this case, we might be interested to know who are the ties, that is, whether they are family, friends, acquaintances, colleagues or neighbours or the strength of the tie, which can vary according to a variety of variables, such as length of relationship or which type of support they provide.

\section{Weak ties}

In the North of Jordan, Syrian women refugees listen and watch songs from Syria, as a way of connecting with people who remained back home. Boswall and Al Alkash (2017) explain how these songs have become a way of connecting refugees who are in exile between themselves and with those back home, increasing social bonding and enabling women refugees to develop a sense of self. Online communication and social computing has been found to be effective in amplifying transnational social capital bonding (Cachia, Kluzer, Cabrera, Centeno, \& Punie, 2007), disseminate disaster preparedness information and warnings and providing a space where community member can locate each other (Houston et al., 2015).

Until the work of Granovetter (1973, 1983), not much attention was given to weak ties. However, now we have come to understand that weak ties can also be very important in one's network because they act as "brokers" within a network, they link different social circles and create bridges which otherwise might have remained absent. Based on the "strength" of weak ties theory, 
individuals with looser and weak ties in their networks rely on bridging social capital. They are less committed and connected to their kin and close friends, but they have access to non-redundant information due to their links with more diverse individuals who can provide different kinds of resources and information. There rely on heterogenous networks, which may serve in facilitating social integration and access to new information, dissemination and social exchange.

Following Hurricane Katrina, victims with a higher level of weak ties were more successful in finding jobs, new houses and schools for their children (Hurlbert et al., 2006). Networks with weaker and sparser ties may be more effective conduits for these instrumental resources. In the context of undocumented immigrants, informal and weak ties can also be indispensable, given their fear of revealing their presence in a specific location, that might lead to deportation and limit their access to information from formal networks (Devillanova, 2008). Access to health care, for instance, is often based on compatriots' informal networks who already know how to access the health care system (Dorn et al., 2011). Accordingly, while on the one hand, conducting SNA with such group of immigrants could be limited due to confidential information; on the other hand, diffusion of information related to health, help with seeking employment or getting their papers in order, could be more efficient if it is disseminated through such informal networks.

In the context of weak ties, there are various SNA metrics that can be used. One approach may be examining the typology of the networks, which would allow the community members to examine how their network is divided. For instance, building non-family bridging connections for those with dense and homogenous network, whereby ties tend to be highly connected with each other and the connections are very similar to ego could improve substantially their capacity to develop diverse connections. Promoting participation in voluntary organisations in the host locations may also be an effective strategy for enabling people to build new ties, although this kind of intervention does not seem to be as effective with residents of poor urban areas who are less likely or willing than their middle-class counterparts to participate in such type of organisations (Hurlbert et al., 2006).

Another approach is using the centrality measure betweenness centrality, to identify brokers in the network. This measure takes into account the number of times a node in the network acts as a bridge along the shortest path between two or more nodes (Wasserman \& Faust, 1994). In other words, interactions between actors may also depend on other actors. These members of the network can act as both brokers and gatekeepers of information. As suggested previously, visualisations can also be effective in enabling people identify weak ties in their network and how such ties can be used to protect them.

Data mining from social computing may also be effective in determining how individuals connect with each other following a crisis and in understanding the different roles being exercised. A social network analysis of the Facebook network in the city of Baton Rouge following the 2016 Louisiana flood found that individuals and agencies/organisations have different roles in social networks during emergency response. Individuals had the highest out-degree, in-degree and eigenvector centralities due to their active role in sharing emergency information with their online friends. In contrast, organisations had the highest betweenness centralities playing a critical role in connecting the city with external social groups or online communities. In this case, examining where most of the activity is taking place may also be an effective strategy in deciding where dissemination messages may be posted, so that they reach the most people rapidly.

\section{Dynamic networks}

For Senait, an Eritrean immigrant woman in her late twenties, the personal network is an ever-changing display of her challenging journey from Turkey to Greece. When the researchers got to know her, her personal network was made up of transnational ties in Eritrea and Europe. A few years later, these ties disappeared from her network, and just a year later, the same ties reappeared in her network (Wissink \& Mazzucato, 2018). Many displaced people like Senait find themselves struggling consciously or unconsciously with changes in their network. Sometimes the changes are provoked by changes in their life, mobility to another refugee hub, and other times by changes in the people or the environment around them, for instance arrival or departures of other migrants.

Following a displacement, a flood, change in policy in places like shelters or camps, the personal network is heavily affected due to radical changes in the person's environment or personal circumstances. The link between critical events and changes in the network is an important aspect of SNA (Bilecen, 2016). The network can vary substantially in terms of size, sources of support, type of ties and composition (Lubbers et al., 2010; Maya Jariego, 2006; Wissink \& Mazzucato, 2018).

During a crisis, networks tend to evolve into atypical structures. Many ties who provided emotional support might disappear from the network to be replaced by many unknown ties suffering the same situation. Typically, there is a high demand for new types of relations (e.g., collaboration and resource sharing) that are specific to disaster response and recovery, and people might have difficulties in identifying who in their network 
could provide such resources. Moreover, the loss of local knowledge could be a great hindrance for survival, especially in places were violence is continuous such as during civil wars. For example, abducted persons lost the capacity to know where to escape because they no longer have access to local knowledge (Baines \& Paddon, 2012). The newly formed personal network is one of the paths which could lead back to some normality.

Temporary shelters, for instance, bring previous unconnected people together, where people develop mutual understanding and trust, out of necessity. Within these ad hoc networks, ties can become very influential. In the absence of previously known strong ties, egos rely on these weak ties to take major decisions, such as moving in and out of the temporary shelters (Varda et al., 2009).

Within such volatile environment, it might be hard to use to the personal network analysis to predict network outcomes as is common in other contexts. However, as previous research based on dynamic networks has suggested, collecting longitudinal data might give us a better understanding of these volatile networks in such circumstance (Lubbers et al., 2010). Visualisations might also be used to see how the networks are changing and to enable people to keep track of the changes in the network. Another approach is to enable people reconstruct their personal network through a retrospective interview. This strategy consists in asking the person to describe what his/her personal network was like at a certain time, normally before the displacement or the emergency or traumatic event, or how personal contacts have been established and have evolved over a period of time, for example, during the migratory process (Maya-Jariego, 2009). Through a guided reflection, using a qualitative interview, the person can reconstruct and describe what the structure of their personal relationships was like and how it has changed. Enabling understanding on the dynamic changes of one's network and why they are happening and designing effective strategies with the people on how to locate support during these changes could provide some protection, in terms of social capital.

\section{Community}

In this section, we will examine how network analysis can enable protection at the community level. Belonging and integration to communities, social relations and informal neighbourhood associations within communities have been positively related with better capacity at developing resilience following a crisis (Haines et al., 1996; Hurlbert et al., 2000). Network metrics can be valuable in identifying leaders, brokers or influencers in a community. In a context of abuse or violence, protection activities might entail engaging with leaders, so as to address the causes of protection threats and negotiate with them restraint in the conduct of war in order to protect civilians (Albrecht, 2018). It can also enable us to monitor how a community evolves over time (how has the community structure changed after a year), following a crisis (how has the community structure changed after a flood) and following intervention (how has the community changed after specific actions/programs have been implemented). Network visualisations could also be used with the community to understand how the community operates, how it is divided and where most intervention and help is needed. Typologies of communities can enable us to determine where protection might be needed. A community which is very sparse would need intervention because as we have seen in previous studies, following a crisis, people within cohesive communities have a higher tendency to recover quicker and better.

\section{Cohesion}

In a study in Taiwan, a location vulnerable to earthquakes, typhoons, landslides and debris flows, Chen, Liu and Chan (2006) highlighted the importance of community cohesion, as a form of protection. Specifically, the researchers explore how through participatory processes which include the strengthening of community resistance, empowering locals to assess risks, developing solutions and establishing organisations to carry out the disaster management tasks as actions, protection as emergency preparedness could be improved. In an another study on the prevention of child labor in Peru, Maya Jariego et al. (2018) found that social relations of family members in the neighbourhood act as a buffer to prevent child labour and hence, protects youngsters, as it increases community integration and social cohesion.

As discussed by Patterson et al. (2010) in their disaster capacity review of Hurricane Katrina, communities are often based on trust and are more likely to succeed in urging cooperative behaviour and teamwork than government. They often play a key role in all stages of disaster preparedness and recovery, given they operate better in getting goods and services efficiently and equitably delivered and also tend to be more flexible, rapid and adaptive. However, as highlighted by the same authors, the same cohesion of a community may also be interpreted wrongly by its members, giving them a false sense of security in locations which can become insecure. Or in a community where information from outside is paramount, a highly dense component connected through one or two nodes in the entire network could lead to a crisis situation if the highly connected person is killed, injured or taken away.

From a structural perspective, cohesion represents the level of connectedness within a network (Wasserman \& Faust, 1994). Density is the most used indicator to measure cohesiveness within a community. Although other 
measures, such as the number of isolated actors and the clustering of nodes in components may also influence in the patterns of inclusiveness (Scott, 2000). As discussed by Martí et al. (2017), another approach which is more bottom-up is based on measuring cohesion through microstructures emerging from dyadic connections established by actors and through which cohesive subgroups are built.

Community cohesion is positively related to effective collaboration, cooperation and operational efficiency when it comes to both crisis preparedness and recovery. It also facilitates decision-making processes and transfer of resources, given the shorter path lengths between actors (Lindelauf, Borm, \& Hamers, 2009). Taking a flood as an example, we might want to consider actions aimed at increasing cohesion in the helping communities, given this has potential in increasing trust, reciprocity, commitment and shared values (Forrest \& Kearns, 2001).

\section{Network maps}

The study conducted by the Joseph Rowntree Foundation, aimed at understanding how the lives of socially excluded people could be improved, is a good example of how network maps could be used to provide protection at the community level. Residents were asked to draw maps of their estates and use colour-coded stickers to illustrate where they took part in formal and informal activities in the neighbourhood and the spaces they frequented and the ones they did not. The maps illustrated visually safe spaces, dangerous places and where most of the activities of residents took place. As an interactive tool, they served as an instrument to intervene with the community, in order to understand why measures taken by government to improve poverty in these neighbourhoods were not yielding positive results.

Network maps are valuable in being a tool which allows interaction with the population, through a participatory process. Being a visual tool, they are easy to conduct and the results are developed by the community in real time. Similar to network visualisations, they also summarise a great variety of data in an image which is easily understood by the community under study.

Participatory processes, whereby community residents are able to identify risks, develop appropriate strategies and solutions and identify responsibilities to manage disasters could help locals' preparedness for future disasters. Through network analysis, members of community can gain understanding of how their community operates. In locations which are notorious for floods, such maps can be used to understand where people tend to move during a crisis and which are the risky locations. So, on the one hand, the maps can be used a guide for people who do not know where to move, and on the other hand, they are useful in identifying the places where most people will move, so as to know where the support camps should be established during or following a crisis. As found by the study about civil wars in Uganda, the construction of landmarks would have enabled abducted victims to know where to escape (Baines \& Paddon, 2012). While in this case, it would be difficult to use network maps with victims, and network maps could be used with people in such risks to enable them to learn how to orient themselves in unknown locations.

Another example would be to identify secure or dangerous locations in a refugee camp, where women have previously reported sexual violence. In this case, these maps could be valuable for women to know which locations should be avoided and also to enable them to develop effective strategies in finding alternative routes or moving in groups, so as to protect themselves from abuse.

\section{Components}

At times, examining the structural relations of a community may be essential in understanding what is happening in a community and where intervention can take place. In a study conducted with American high school students about their romantic relations over an 18month period, it was found that the network had one single component which connected $52 \%$ of the students in one long chain (Bearman, Moody, \& Stovel, 2004). This tree-like component meant that one student had a relation with a second student, who had a relation with a third student (Fig. 2). Unlike adult networks, there was no core group of highly sexually active students. The relations were based on long chains of connections that spread through the community, with few students directly sharing the same partner. Without realizing it, a high school student with one single partner might still be part of this large component. Even though the student is not promiscuous, she might still be in many paths of potentially sexually transmitted diseases. Specifically, a student with one partner in a big component is at a higher risk of contracting a disease than a student with multiple partners who is embedded in a smaller sparse component.

In this case, the typical intervention aimed at the core group who are sexually very active and who tend to be the main conduits of disease does not work. Within such a component, there are no hubs the intervention could target, whose change in behaviour can have an effect on the community as a whole. Moreover, the tree-like structure may break at any time resulting in small disconnected components. Accordingly, the design of the intervention for protecting these young people needs to be broad in encompassing the entire population, taking into account that anyone can be a conduit of a sexually transmitted disease. 


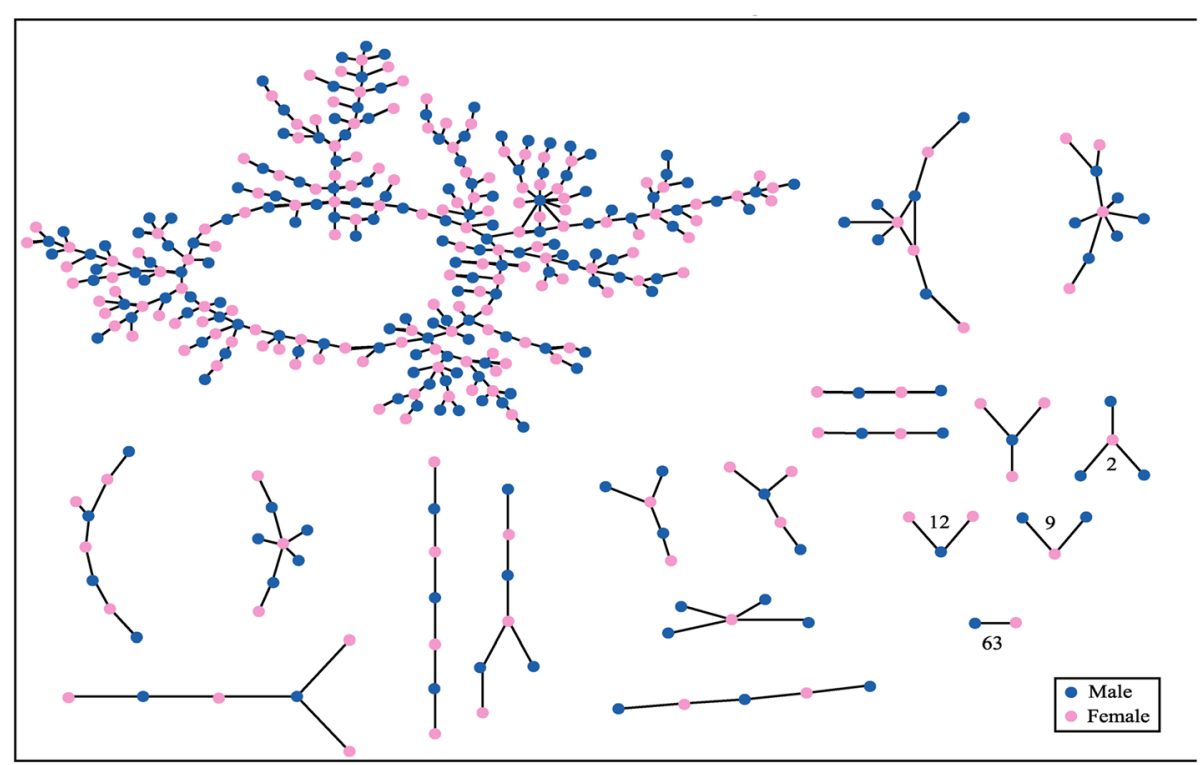

Fig. 2 The structure of romantic and sexual relationships of high school students, whereby each circle represents a student and the lines connecting the students represent the romantic relationships which took place at any point during the 6 months preceding the interview (Bearman et al., 2004)

In this example, we see how having an accurate sense of the structural relations of community, such as components and cliques can be valuable when it comes to designing effective intervention and protection. Let us say we want to examine the level of trust in a specific shelter and we discover two types of components: a tree-type component and a highly dense component. With the former component, we learn that trust is limited and only a few people trust each other. In contrast, with the latter component, most of the people trust each other. Hence, if our aim is to bring the community together to enable it to protect itself through resilience mechanisms, different strategies would need to be undertaken with the different components.

\section{Community coalitions}

Effective coalitions amongst different stakeholders participating in a disaster are also found to have positive implications when it comes to intervention. As discussed by Fulk et al. (1996), collaboration amongst organisations provide a form of informal infrastructure which contribute toward an aspect of community resilience. Community resilience through organisations may be expressed through the reconfiguring social networks, self-organisation, redundancy, proactive practices and restoring trust in information as found in a study looking into the disaster recover in wartime Iraq (Mark, Al-Ani, \& Semaan, 2009). Interorganisational networks in emergencies have been found to facilitate flow of information, to be in a better position to develop trust and disseminate information rapidly. Following disasters, the coalitions of the health care sector's response and recovery from disasters have been found to be critical (Acosta et al., 2015). The diversity of partners in such coalitions allows better resolution to complex problems and sharing of resources.

Network analysis could serve to examine and operationalise community coalitions as interorganisational networks (Maya Jariego, 2016). It can be used as a tool for planning and monitoring humanitarian protection, enabling the different agents to have a clear role and not to overlap in each other's work. It has also been found to be effective in improving the capacity of donors in evaluating the action, allowing a better understanding of the relationships between programme actors (Nascimbeni, 2018). Improving the level of coordination among humanitarian aid organisations can optimise the flow of resources among agencies and increase effectiveness of aid operation. As Galaskiewizc (1985) argues, organisations might want to enter inter-organisational transaction but also want to maintain their autonomy. Moreover, it might enable the classifying of the different agencies into groupings or typologies, which as Acosta et al. (2015) found in the health sector could be useful for tailoring support according to the relative capabilities.

It might also be used to examine the position of the network actors and their influence in the network. In some contexts, it might be insightful to understand who is central, who has the most influence or who is able to provoke change, based on indicators of centrality, 


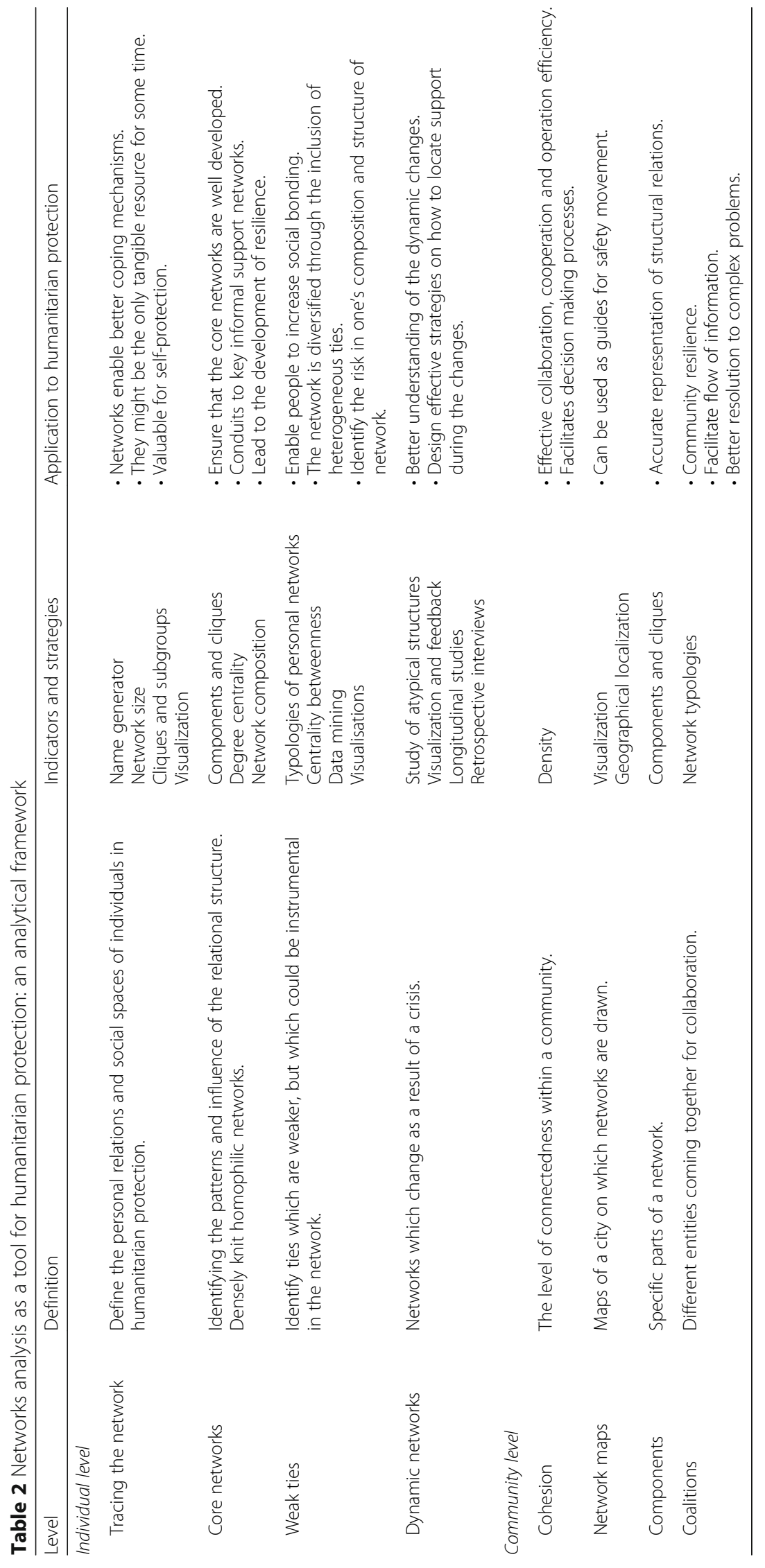


brokerage and other assessment of key players (Valente, 1995). If our objective is to disseminate essential information in a community, for instance, avoiding risks following an earthquake, it might be useful to identify the hubs in the community using degree centrality, given these people are more likely to spread the information rapidly. On the other hand, if we want to reach different parts of the community, identifying the brokers in the community might be more effective.

As we have seen in the study in Mozambique, coalitions tend to form a centre-periphery structure. These are networks which are highly interconnected in the middle and sparse on the edges. Generally, the centre is formed with highly active agencies, who tend to take a leadership role, especially in the initial phase of the intervention and who are also active in promoting relations between the agencies, which keep increasing progressively (Maya Jariego, 2016).

The use of network analysis for humanitarian protection has been summarised in Table 2. The analytical framework is aimed as providing the different levels of network analysis application, the indicators and strategies that can be used and their application to humanitarian protection.

\section{Final remarks}

Social network analysis enables the study of the structure of relationships at different individual, community and organisational levels and with different entities or subjects (Kadushin, 2012). The versatility of network analysis facilitates the investigation and understanding of different social processes in different contexts, through the operationalization of indicators of structure and composition of the networks and in combination with other procedures and methodologies. In this review, we have identified some basic strategies of network analysis that can be applied to the study of humanitarian protection processes. We have illustrated how the analysis of the relational processes between the different actors involved in humanitarian aid allows us to analyze the dynamics of exchange, leadership and affiliation between these actors. Moreover, they facilitate the design and implementation of effective intervention strategies.

First, it facilitates the description of the personal relationships of people in need of humanitarian protection, as well as planning strategies for the construction or reconstruction of significant support relationships. This allows, first, to locate resources in these networks, so that they can be mobilized in emergency or displacement contexts. For example, it is possible to determine the social capital present in networks based on indicators of centrality and cohesion. On the other hand, it facilitates the description of the evolution of the structure and composition of personal relationships. In contexts of emergency or catastrophe, the personal network can be an indicator of the magnitude of the individual and collective impact of the traumatic event and, therefore, can help to establish the priority needs for intervention. In addition, it provides an objective indicator of evaluation that can help to understand the effects of the policies and programs implemented in these contexts.

The analysis of networks also allows analyzing processes at the community level. Identification of cohesion or leadership dynamics helps to understand the level of preparedness of the community for disasters or emergency situations. Community cohesion and the strength of social ties have proven to be one of the most important variables in disaster preparedness, response and recovery (Moore et al., 2004). It also facilitates the identification and awareness of existing resources or needs, which helps to create spaces for collaboration and exchange to improve this preparation. We have also seen how network maps allow people to participate in a process, whereby risky or dangerous locations are identified.

An accurate sense of the structural relations of community, such as components and cliques, is instrumental when it comes to designing effective intervention and protection. In this sense, network analysis unfolds important aspects of data which might be hard to extract from other methodologies. Finally, we have seen how network analysis is useful in planning and monitoring humanitarian protection when it comes to community coalitions.

In conclusion, the analysis of social networks provides a theoretical and methodological focus on relations, which facilitates the understanding of the dynamics of exchange that occur between the different actors involved in humanitarian protection. These dynamics are behind the effectiveness of a large part of the policies and programs within this scope (Balcik, Beamon, Krejci, Muramatsu, \& Ramirez, 2010; Stephenson Jr \& Schnitzer, 2006).

\section{Abbreviations \\ NGOs: Non-government organisations; SNA: Social network analysis; PNA: Personal network analysis}

\section{Acknowledgements \\ The authors would like to thank [author] Isidro Maya Jariego for his valuable feedback on an earlier draft of the article.}

\section{Authors' contributions}

$\mathrm{RC}$ has written the first version of the article and $\mathrm{DH}$ has evaluated the first drafts and also contributed to the analysis and conclusions of the article. The author(s) read and approved the final manuscript.

\section{Funding}

No specific funding was used for this article.

\section{Availability of data and materials}

Data sharing is not applicable to this article as no datasets were generated or analysed during the current study.

Competing interests

The authors declare that they have no competing interests. 
Received: 19 July 2019 Accepted: 23 March 2020

Published online: 03 June 2020

\section{References}

Acosta J, Howard S, Chandra A, Varda D, Sprong S, Uscher-Pines L (2015) Contributions of health care coalitions to preparedness and resilience: perspectives from hospital preparedness program and health care preparedness coalitions. Disaster Med Public Health Preparedness 9(6):690-697. http://dx.doi.org.ejournals.um.edu.mt/10.1017/dmp.2015.134

Addison, S. (2009). Protecting people in conflict and crisis: responding to the challenges of a changing world. Retrieved from Oxford: http://www.rsc.ox.ac uk/pdfs/reflectionssimon.pdf

Adger WN (2003) Social capital, collective action, and adaptation to climate change. Econ Geography 79(4):387-404. https://doi.org/10.1111/j.1944-8287. 2003.tb00220.x

Albrecht F (2018) Natural hazard events and social capital: the social impact of natural disasters. Disasters 42(2):336-360. https://doi.org/10.1111/disa.12246

Baines E, Paddon E (2012) This is how we survived': civilian agency and humanitarian protection. Security Dialogue 43(3):231-247. https://doi.org/10 1177/0967010612444150

Balcik B, Beamon BM, Krejci CC, Muramatsu KM, Ramirez M (2010) Coordination in humanitarian relief chains: practices, challenges and opportunities. Int J Production Econ 126(1):22-34. https://doi.org/10.1016/j.ijpe.2009.09.008

Barabasi A-L (2002) Linked: the new science of networks. Perseus, Cambridge, MA

Bearman PS, Moody J, Stovel K (2004) Chains of affection: the structure of adolescent romantic and sexual networks. Am J Sociol 110(1):44-91. https:// doi.org/10.1086/386272

Bernard HR, Ryan GW (2010) Analyzing qualitative data. Sage Publications, Los Angeles, Thousand Oaks, CA

Bilecen B (2016) A personal network approach in mixed-methods design to investigate transnational social protection. Int Rev Social Res 6(4):233-244

Boswall K, Al Akash R (2017) Listening, resistance and mobile phone playlists: musical listening practices of Syrian women living as refugees in Northern Jordan. Social Dynamics 43(2):167-183. https://doi.org/10.1080/02533952.2017.1368437

Cachia R, Kluzer S, Cabrera M, Centeno C, Punie Y (2007) ICT, social capital and cultural diversity: report on a Joint IPTS-DG INFSO Workshop held in Istanbul (Turkey), 25 April 2007. European Commission - Joint Research Centre Institute for Prospective Technological Studies, Seville

Cachia R, Maya Jariego I (2018) Mobility types, transnational ties and personal networks in four highly skilled immigrant communities in Seville (Spain). Social Networks 53:111-124. https://doi.org/10.1016/j.socnet.2017.03.014

Cassel J (1974) Psychosocial processes and stress: theoretical formulations. Int J Health Services 4:471-482

Chatters LM, Taylor RJ, Neighbors HW (1989) Size of informal helper network mobilized during a serious personal problem among Black Americans. J Marriage Family 51(3):667-676. https://doi.org/10.2307/352166

Chen L-C, Liu Y-C, Chan K-C (2006) Integrated community-based disaster management program in Taiwan: a case study of Shang-An Village. Nat Hazards 37(1):209. https://doi.org/10.1007/s11069-005-4669-5

Cobb S (1976) Social support as a moderator of life stress. Psychosomatic Med 38(5):300-314

Cohen S, Syme SL (1985) Social support and health. Academic Press, Orlando Fla.

Committee I-AS (2002) Growing the sheltering tree: protecting rights through humanitarian action, programmes and practices gathered from the field. IASC, Geneva

Devillanova C (2008) Social networks, information and health care utilization: evidence from undocumented immigrants in Milan. Journal of Health Economics 27(2):265-286. https://doi.org/10.1016/j.jhealeco.2007.08.006

Domínguez S, Hollstein B (Eds.) (2014) Mixed methods social networks research: design and applications. Cambridge University Press, Cambridge.

Dorn T, Ceelen M, Tang M-J, Browne JL, de Keijzer KJ, Buster MC, Das K (2011) Health care seeking among detained undocumented migrants: a cross-sectional study. BMC Public Health 11(1):190. https://doi.org/10.1186/1471-2458-11-190

Ellison NB, Steinfield C, Lampe C (2007) The benefits of Facebook "Friends:" social capital and college students' use of online social network sites. J Computer Mediated Commun 12(4):1143-1168

European Commission. (2016). Humanitarian protection: improving protection outcomes to reduce risks for people in humanitarian crises: DG ECHO, Thematic Policy Document Number 8. Retrieved from https://ec.europa.eu/echo/sites/echo-site/files/policy_guidelines humanitarian_protection_en.pdf
Fernandez-Peña R, Molina JL, Valero O (2018) Personal network analysis in the study of social support: the case of chronic pain. Int. J. Environ. Res. Public Health 15(12):2695

Forrest R, Kearns A (2001) Social cohesion, social capital and the neighbourhood. Urban Stud 38:2125-2143. https://doi.org/10.1080/00420980120087081

Freeman LC (2004) The development of social network analysis: a study in the sociology of science. Empirical Press, Vancouver, BC

Fulk J, Flanagin A, Kalman M, Monge P, Ryan T (1996) Connective and communal public goods in interactive communication systems. Commun Theory 6(6087)

Galaskiewicz J (1985) Professional Networks and the Institutionalization of a Single Mind Set. Am Sociol Rev 50(5):639-658. Retrieved March 31, 2020, from www.jstor.org/stable/2095379.

Gamper M, Schönhuth M, Kronenwett M (2012) Bringing qualitative and quantitative data together: collecting network data with the help of the software tool VennMaker. In: Safar M, Mahdi K (eds) Social Networking and Community Behavior Modeling: Qualitative and Quantitative Measures. Hershley, PA, pp 193-213

Giossi Caversazio S (2001) Strengthening protection in war: a search for professional standards. International Committee of the Red Cross, Geneva

Granovetter MS (1973) The strength of weak ties. Am J Commun Psychol 78:1360-1380

Granovetter MS (1983) The strength of weak ties: a network theory revisted. Sociol Theory 1:201-233

Hafner-Burton EM, Kahler M, Montgomery AH (2009) Network analysis for international relations. Int Organization 63(3):559-592

Haines V, Hurlbert J, Beggs J (1996) Exploring the determinants of support provision: Provider characteristics, personal networks, community contexts, and support following life events. J Health Social Behav 37(3):252-264. https://doi.org/10.2307/2137295

Herz A (2015) Relational constitution of social support in migrants' transnational personal communities. Social Networks 40:64-74

Houston JB, Hawthorne J, Perreault MF, Park EH, Goldstein Hode M, Halliwell MR et al (2015) Social media and disasters: a functional framework for social media use in disaster planning, response, and research. Disasters 39(1):1-22. https://doi.org/10.1111/disa.12092

Hurlbert, J. S., Beggs, J. J., \& Haines, V. (2006). Bridges over troubled waters: what are the optimal networks for Katrina's victims?

Hurlbert JS, Haines VA, Beggs JJ (2000) Core networks and tie activation: what kinds of routine networks allocate resources in nonroutine situations? Am Sociological Rev 65(4):598-618. https://doi.org/10.2307/2657385

Jaspars S, O'Callaghan S (2010) Livelihoods and protection in situations of protracted conflict. Disasters 34(s2):S165-S182. https://doi.org/10.1111/j.14677717.2010.01152.x

Kadushin C (2012) Understanding social networks: theories, concepts and findings. Oxford University Press, New York

Kingsbury MD, Bhatta PM, Castellani B, Khanal A, Jefferis E, Hallam SJ (2018) The personal social networks of resettled Bhutanese refugees during pregnancy in the United States: a social network analysis. J Commun Health. https://doi. org/10.1007/s10900-018-0518-9

Li Z, Chen Y, Suo L (2015) Impacts of social network on therapeutic community participation: a follow-up survey of data gathered after Ya'an earthquake. Iranian journal of public health 44(1):68-78

Lindelauf R, Borm P, Hamers H (2009) The influence of secrecy on the communication structure of covert networks. Social Networks 31(2):126-137. https://doi.org/10.1016/j.socnet.2008.12.003

Lubbers MJ, Molina JL, Lerner J, Brandes U, Avila J, McCarty C (2010) Longitudinal analysis of personal networks. The case of Argentinean migrants in Spain. Social Networks 32(1):91-104

Marin A, Hampton KN (2007) Simplifying the personal network name generator. Field Methods 19(2):163-193. https://doi.org/10.1177/1525822×06298588

Mark, G., Al-Ani, B., \& Semaan, B. (2009). Resilience through technology adoption: merging the old and the new in Iraq. Paper presented at the 27th international conference on Human factors in computing systems, New York.

Marsden, P (1987) Core discussion networks of americans. Am Sociol Rev 52(1): 122-131.

Martí J, Bolíbar M, Lozares C (2017) Network cohesion and social support. Social Networks 48:192-201. https://doi.org/10.1016/j.socnet.2016.08.006

Maya Jariego I (2006) Web of compatriots: relationship networks among immigrants. In: Pérez Pont JL (ed) Geografías del desorden. Migración, alteridad y nueva esfera social. Universidad de Valencia, Valencia, pp 257-276

Maya Jariego I (2016) 7 uses of network anlaysis in community intervention. REDES 27(2):1-10 
Maya Jariego I, Holgado D (2015) Living in the metropolitan area. Correlation of interurban mobility with the structural cohesion of personal networks and the originative sense of community. Psychosocial Intervention 24(3):185-190

Maya Jariego I, Holgado D, Márquez López E, Santaloya Soriano FJ (2018) The community role of schools in Jicamarca and Villa El Salvador (Peru): crosscutting behavior settings in personal networks. Psychosocial Intervention 27(1):1-11

Maya-Jariego I (2009) Mesas de paisanaje: the network of relationships of immigrants. NETWORKS Hispanic Magazine Analysis Soc Networks 17:273-303

Maya-Jariego I, Holgado D (2015) Network analysis for social and community interventions (special issue). Psychosocial Intervention 24

McCarty C, Molina JL, Aguilera C, Rota L (2007) A comparison of social network mapping and personal network visualization. Field Methods 19(2):145-162

McPherson M, Smith-Lovin L, Brashears ME (2006) Social isolation in America: changes in core discussion networks over two decades. Am Sociological Rev 71:353-375

Menjivar C (2002) The ties that heal: Guatemalan immigrant women's networks and medical treatment. Int Migration Rev 36(2):437-466

Moore S, Daniel M, Linnan L, Campbell M, Benedict S, Meier A (2004) After hurricane floyd passed: investigating the social determinants of disaster preparedness and recovery. Family Commun Health 27(3):204-217

Moore S, Eng E, Daniel M (2003) International NGOs and the role of network centrality in humanitarian aid operations: a case study of coordination during the 2000 Mozambique floods. Disasters 27(4):305-318. https://doi.org/10. 1111/j.0361-3666.2003.00235.x

Nascimbeni $F$ (2018) The importance of networking in development co-operation: a social network analysis-based evaluation of an international development programme. Dev Policy Rev 36(S1):O400-0413. https://doi.org/10.1111/dpr. 12292.

Nakagawa Y, Shaw R (2004) Social capital: a missing link to disaster recovery. Int J Mass Emerg Disasters 22(1):5.34

O'Callaghan S, Pantuliano S (2007) Protective action: incorporating civilian protection into humanitarian response, HPG Report. 26: Humanitarian Policy Group, Overseas Development.

Patterson O, Weil F, Patel K (2010) The role of community in disaster response: conceptual models. Population Res Policy Rev 29(2):127-141. https://doi.org/ 10.1007/s11113-009-9133-x

Putnam, RD (2000) Bowling alone: the collapse and revival of American Community Simon and Schuster.

Quarantelli E, Dynes R (1977) Response to social crisis and disaster. Annual Review of Sociology 3:23.

Ryan L, D'Angelo A (2018) Changing times: migrants' social network analysis and the challenges of longitudinal research. Social Networks 53:148-158. https:// doi.org/10.1016/j.socnet.2017.03.003

Shavit Y, Fischer CS, Koresh Y (1994) Kin and Nonkin under Collective Threat: Israeli Networks during the Gulf War*. Social Forces 72(4):1197-1215. https:// doi.org/10.1093/sf/72.4.1197

Scott J (2000) Social network analysis : a handbook. Sage, Thousands Oaks, CA

Stephenson M Jr, Schnitzer MH (2006) Interorganizational trust, boundary spanning, and humanitarian relief coordination. Nonprofit Manag Leadership 17(2):211-233. https://doi.org/10.1002/nml.144

Suter B (2012) Social networks in transit: experiences of Nigerian migrants inlstanbul. J. Immigr. Refug. Stud. 204-222

Thomas FC, Roberts B, Luitel NP, Upadhaya N, Tol WA (2011) Resilience of refugees displaced in the developing world: a qualitative analysis of strengths and struggles of urban refugees in Nepal. Conflict and Health 5:20-20. https://doi. org/10.1186/1752-1505-5-20

Umberson D, Montez JK (2010) Social relationships and health: a flashpoint for health policy. J Health Soc Behav 51(1 suppl):S54-S66. https://doi.org/10.1177/ 0022146510383501

Valente TW (1995) Network models of the diffusion of innovation, Hampton Press, Cresskill, NJ.

Valente TW, Palinkas LA, Czaja S, Chu KH, Brown CH (2015) Social network analysis for program implementation. PloS one 10(6)

Van Wijk J (2010) Luanda - Holanda: irregular migration from Angola to the Netherlands. Int. Migr. 48:1-30

Varda DM, Forgette R, Banks D, Contractor N (2009) Social network methodology in the study of disasters: issues and insights prompted by post-Katrina research. Population Res Policy Rev 28(1):11-29

Wasserman S, Faust K (1994) Social network analysis: methods and applications. Cambridge University Press, Cambridge
Wellman B (1979) The community question: the intimate networks of East Yorkers. Am J Commun Psychol 84(5):1201-1231

Wellman B, Wortley S (1990) Different strokes from different folks: community ties and social support. Am J Sociol 96(3):558-588

Wissink M, Mazzucato V (2018) In transit: changing social networks of subSaharan African migrants in Turkey and Greece. Social Networks 53:30-41. https://doi.org/10.1016/j.socnet.2017.03.005

\section{Publisher's Note}

Springer Nature remains neutral with regard to jurisdictional claims in published maps and institutional affiliations.

\section{Submit your manuscript to a SpringerOpen ${ }^{\circ}$ journal and benefit from:}

- Convenient online submission

- Rigorous peer review

- Open access: articles freely available online

High visibility within the field

- Retaining the copyright to your article

Submit your next manuscript at $\boldsymbol{\nabla}$ springeropen.com 